\title{
RE-EVALUATION OF VULVOVAGINAL TRICHOMONIASIS AMONG WOMEN IN NIGER DELTA REGION, NIGERIA
}

\author{
GLORIA NGOZIKA WOKEM AND CECILIA BEKEE NDUKWU
}

(Received 30 October 2014; Revision Accepted 17 March 2015)

\begin{abstract}
The status ofa neglected, common tropical protozoan parasitic flagellate, Trichomonas vaginalis, causing vulvovaginal trichomonias is (VVT) was re-evaluated among female subjects in Port Harcourt, Rivers State, Nigeria. The study area consisted University of Port Harcourt Teaching Hospital (UPTH), Braithwaite Memorial Specialist Hospital (BMSH) and Rivers State University of Science and Technology (RSUST), all in Port Harcourt, Niger Delta Region. Informed consent was sought and obtained before sample collection. Standard parasitological techniques were employed in vaginal swab and urine analysis. Two hundred and forty female subjects, aged 11-60 years were examined in 2014, out of which $22.5 \%$ were infected whereas in the precious study in 2006, the prevalence was $10 \%$ out of 500 subjects. UPTH had more VVT rates $(9.7 \%, 30 \%)$ than BMSH $(8 \%, 18.8 \%)$, in both studies respectively, although the infection is not location dependent $(P>0.05)$. Age group 11-20 years $(46.7 \%)$ had the highest infection rate inlatter with age group 51-60 years $(5 \%)$ as the least; age group $19-29$ years had $(16.5 \%)$ as the highest in the former. Occupational prevalence shows that undergraduates and students were more infected with VVT $(40 \%)$ and $(25 \%)$ than others in latter while traders were most infected $(11.1 \%)$ in the former, although VVT was not significantly $(p>0.05)$ occupation related. Non-pregnant subjects $(26.6 \%)$ were more infected than pregnant ones (14\%);statistical analysis showed that pregnancy has close association with VVT butit is not pregnancy dependent $(p>0.05)$. The unmarried $(30 \%)$ had higher prevalence than married $(11.7 \%)$. The results showed that Trichomonas vaginalis can tolerate wide range of acidic $\mathrm{pH}$ (4-5.5). The prevalence of VVT is on the increase; there is need for more awareness campaign and action plan for the control and elimination of this neglected common tropical disease of the youth.
\end{abstract}

KEYWORD: Vulvovaginal trichomoniasis, women, Niger Delta Region, re-evaluation, upsurge.

\section{INTRODUCTION}

Vulvovaginal trichomoniasis (VVT) is a neglected chronic flagellate infection of urogenital system endemic in the tropical countries. It is a sexually - transmitted disease with significant public health importance, globally distributed including Nigeria and Rivers State in particular (Anosike, et al; 2004; Wokem, 2006). In women, the anatomical part commonly affected is the urogenital tract (vulva, vagina and urethra). Trichomoniasis is the most common curable sexually - transmitted infection with global prevalence of $8.1 \%$ among women (WHO, 2011).It issubject to denaturation on heating to a temperature above $40^{\circ} \mathrm{C}$,exposure to direct solar rays in the tropics, and changes in osmotic pressure have harmful effects on it (Wokem,2006). This is a follow up study of VVT with the aim of re-evaluation and comparison of the past and current status, in order to be able to predict its future.

An estimated 173 million new cases of trichomoniasis occur globally each year making it the most common non-viral sexually transmitted disease in the world (Dennis etal; 2012). The annual incidence of trichomoniasis in the United States is estimated to be three to five million with a $3.1 \%$ prevalence rate among women of reproductive age (Sutton et al; 2007). A cross sectional study conducted in Ivory Coast, Tanzania, Zaire and Kenya confirmed this fact (Sorvillo et al; 2001; Dennis et al; 2012; Kissinger et al; 2013).The prevalence of this protozoan infection ranged from $9 \%$ to $30 \%$ in Nigeria (Anosike et al; 2004; Wokem, 2006) and diagnostic tests sensitivity may extend upto $70 \%$ using polymerase chain reaction (PCR) diagnostic method. Incidence of the trichomoniasis in a normal population ranges from $2 \%$ to $15 \%$, although the incidence varies with age, marital status and race (Vaisrub, 1989). It was reported that in United States of America, 23 out of 50 patients with trichomoniasis were asymptomatic (Krieger, 1993).

This infection has been implicated as causing low birth weight, preterm abortion and as a co-factor in Human Immune Deficiency Virus (HIV) transmission and acquisition (Sorvillo et al., 2001). Data from studies conducted in Africa have shown an association between trichomoniasis and HIV infection, suggesting two to three fold increase in HIV transmission. However, the infection was rare among virgins (Wokem, 2006). Increase cervical shedding of HIV has been shown to be

Gloria Ngozika Wokem, Parasitology and Public Health Unit, Department of Animal and Environmental Biology, College of Natural and Applied Sciences, University of Port Harcourt,P.M.B.5323,Port Harcourt, Rivers State, Nigeria.

Cecilia Bekee Ndukwu, Medical Microbiology Unit, Medical Laboratory Department.Braithwaite Memorial Specialist Hospital, Port Harcourt, Rivers State, Nigeria. 
associated with cervical inflammation and substantially increased urethra viral loads have been documented in men with trichomoniasis (Kreiss et al; 1994). Women in their reproductive ages are more prone to the infection due to the high production of estrogen hormone that produces glycogen in the vaginal mucosa which the parasite is able to utilize (Anosike et al; 2004).

Trichomonas vaginalis infection typically elicits an aggressive local cellular immune response with inflammation of the vaginal epithelium and exo-cervix in women and urethral of men (Sardana et al; 1994). It can cause punctate mucosal hemorrhage (Fouts; Kraus; 1980). It is also reported that Trichomonas vaginalis has the capacity to degrade secretory leukocyte protease inhibitor, a product known to block HIV cell attachment (Hobbs et al; 1999), which may also promoteHIV transmission. Some rare cases of vaginal, urinary tract, nasal and respiratory infections with $T$. vaginalis have been reported in newborns of mothers infected with this flagilate (Schwandt, et al; 2008).

The exact mechanism of the pathogensis is still not fully elucidated and it appears to be multifactorial, depending on the inherent virulence of the parasite and the host factors. The main mechanism postulated seem to be mediated by cell to cell adhesion, hemolysis, excretion of soluble proteinase, pore forming protein and cell detaching factor (Arora and Arora, 2008).

\section{MATERIALS AND METHODS}

The previous (2006) and present (2014) study populations were drawn from Braithwaite Memorial Specialist Hospital (BMSH), and University of Port Harcourt Teaching Hospital (UPTH), except that the former included Rivers State University of Science and Technology (RSUST), all of the sites are in Port
Harcourt, Rivers State, Nigeria. The population consists of secondary school girls, teachers, female undergraduates, female petty traders and others. The population size for the present study was 240 subjects, comprising 160 from BMSH and80 from UPTH while the former was 500. RSUST had 140, whereas UPTH and BMSH were 184 and 176 subjects respectively. The study populations vary in age, sex, occupation and social background but were from the same part of Niger Delta Region of Rivers State.

Ethical clearance was sought and obtained from the Institutions as well as informed consent from the volunteers before sample collection. High vaginal swabs (HVS) were collected from the volunteers with the aid of sterile swab stick. Fresh urine (FU) was also collected from them in clean wide mounted sample containers. The specimens were analyzed fresh to ensure viability and motility of Trichomonas vaginalis trophozoites.

Each vaginal specimen obtained with the swabstick was transferred to a $\mathrm{pH}$ paper (Phydrion paper; micro Essential Laboratory, Brooklyn, New York) and independently compared the colour of the $\mathrm{pH}$ paper with the standard $\mathrm{pH}$ reference chart. After the $\mathrm{pH}$ determination, each specimen was agitated in approximately $1 \mathrm{ml}$ of normal saline in separate test tubes. A drop of each preparation was transferred to a microscope slide topped with coverslip. The preparation was viewed at $\times 10$ and $\times 40$ microscope magnifications. A jerky motile organism was typical of Trichomonas vaginalis. About $7 \mathrm{ml}$ of homogenized fresh urine sample was centrifuged at 2,000 r. p. m using MSE centrifuge for 3 minutes, each deposit was viewed under $\times 10$ and $\times 40$ microscope magnifications. Chi-square and heterogeneity chi-square tests were used to further analyze the data generated.

\section{RESULTS}

Table 1: Comparative prevalence of Trichomonas vaginalisin swab and urine in the study population.

\begin{tabular}{lllll} 
Date & $\begin{array}{l}\text { No. of swab } \\
\text { examined }\end{array}$ & $\begin{array}{l}\text { No. of swab } \\
+ \text { ve }(\%)\end{array}$ & $\begin{array}{l}\text { No. of sample } \\
\text { examined }\end{array}$ & $\begin{array}{l}\text { No. of urine sample } \\
+ \text { ve }(\%)\end{array}$ \\
\hline 2006 & 300 & $30(10)$ & 200 & $12(6)$ \\
2014 & 240 & $54(22.5)$ & 240 & $44(18.3)$ \\
Total & 540 & $84(15.6)$ & 440 & $56(12.7)$
\end{tabular}

$\left(d f=1, X^{2}\right.$ cal.2.4, $X^{2}$ tab. $=3.84, P>0.05$ for swab). $\left(d f=1, X^{2}\right.$ cal. $1.5, X^{2}$ tab. $=3.84, P>.05$ for urine $)$.

Table 1, shows the comparative prevalence of Trichomonas vaginalisin swab and urine samples in the study population for the year 2006 and 2014. Out of 240 female subjects screened for VVT in 2014, using HVS and FU samples, $54(22.5 \%)$ and $44(18.3 \%)$ were infected respectively. In the former (2006), swab was
$30(10 \%)$ while urine had $12(6 \%)$ positive for VVT.The latter (2014) studyon VVT had higher statistically significant infection ratefor both samples $(P<0.05)$ than the former. Comparatively, infection rate was slightly higher with HVS (15.6\%) than FU (12.7\%) though the difference was not statistically significant $(p>0.05)$. 


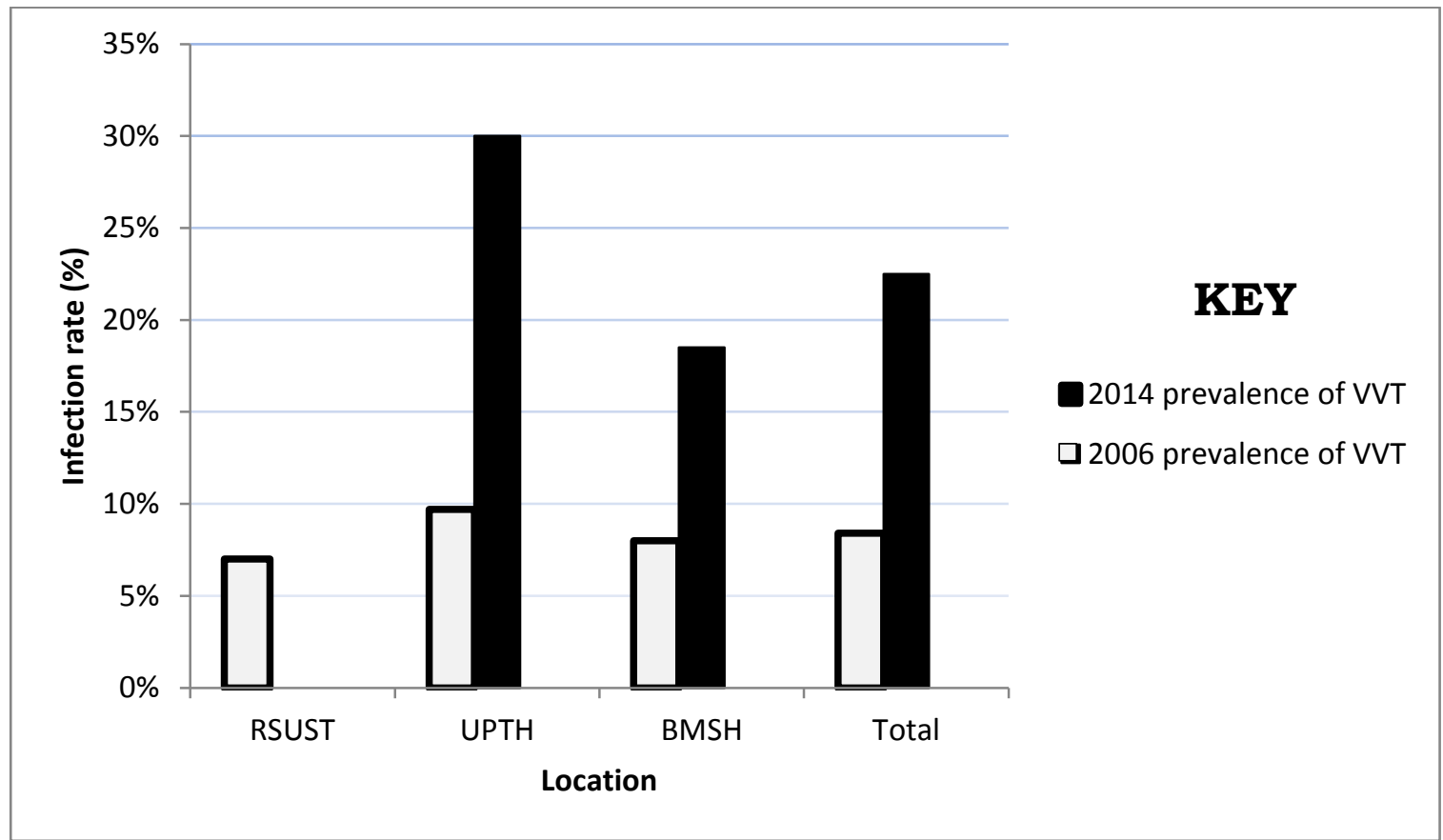

Figure 1: Location related prevalence of VVT in the study populations of 2006 and 2014.

Location related prevalence of VVT in the year 2006 and 2014 (Figure 1) shows that UPTH had the highest prevalence $9.7 \%$ and $30 \%$ in both years respectively. The least prevalence was recorded in RSUST in 2006; the latter work did not include RSUST sub population. In the two common study locations UPTH and BMSH, VVT was significantly higher in $2014(\mathrm{P}<0.05)$. The total prevalence of VVT in 2006 was $8.4 \%$ as against $22.5 \%$ in 2014.

Table 2: Pregnancy status related prevalence of Trichomonas vaginalis in the study population 2014.

\begin{tabular}{lccc} 
Status of subject & No. examined & No. + ve $(\%)$ & No. - ve $(\%)$ \\
\hline Pregnant women & 100 & $14(14.0)$ & $86(86.0)$ \\
Non-pregnant women & 140 & $40(26.6)$ & $100(71.4)$ \\
Total & 240 & $54(22.5)$ & $186(77.5)$ \\
& $\left(\mathrm{df}=1, \mathrm{X}_{2}\right.$ Cal. $=3.72, \mathrm{X}_{2}$ tab. $\left.=3.84, \mathrm{P}=0.05\right)$
\end{tabular}

Pregnancy status prevalence in Table 2 , shows that out of 100 pregnant women screened, $14(14.0 \%)$ were positive for VVT. The non-pregnant subjects screened were 140 , out of which $26.6 \%$ were positive for $T$. vaginalis infection. Although there is a close relationship between VVT and pregnancy but the chi-square test showed that it was not pregnancy dependent $(\mathrm{df}=1$,

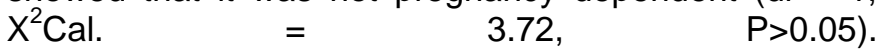




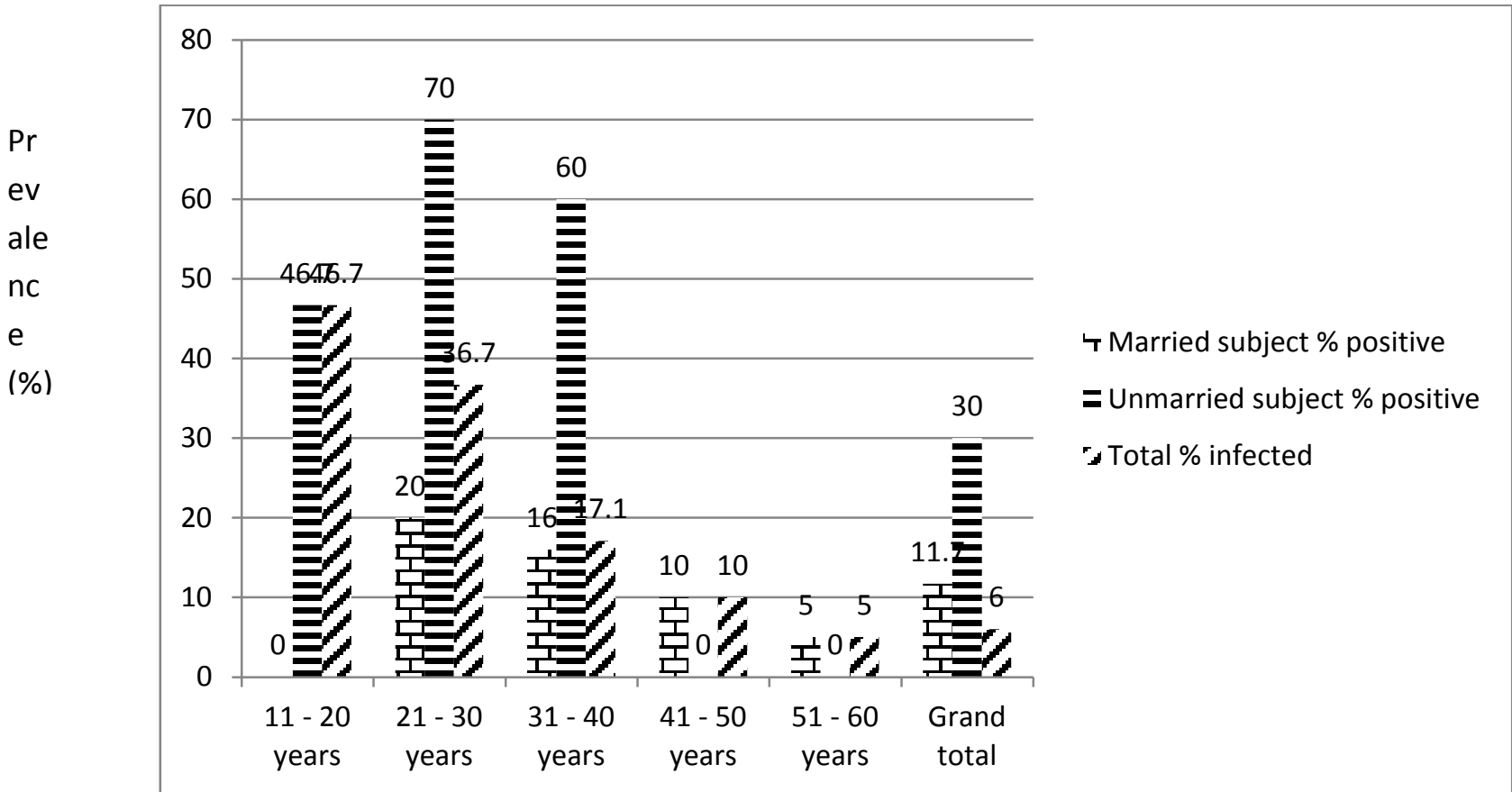

Age groups (years) and marital status

Figure 2a: Age and marital status prevalence of vulvovaginal trichomoniasis in the study population, 2014.

From figure $2 \mathrm{a}$, it is observed that, $11-20$ years age group had the highest total infection rate $(46.7 \%)$, followed by $21-30$ years age group (36.7\%) while the least prevalence was in 51 - 60 years age group (5\%). The unmarried had infection rate of $46.7 \%, 70 \%$, and $60 \%$ corresponding to age group 11 to 20,21 to 30 years and 31 to 40 years respectively. It is also observed that age group 51 to 60 years had the least infection and no unmarried subject was screened in age group $41-50$ years and 51 to 60 years. The highest infection rate was $70 \%$ from the unmarried subjects.

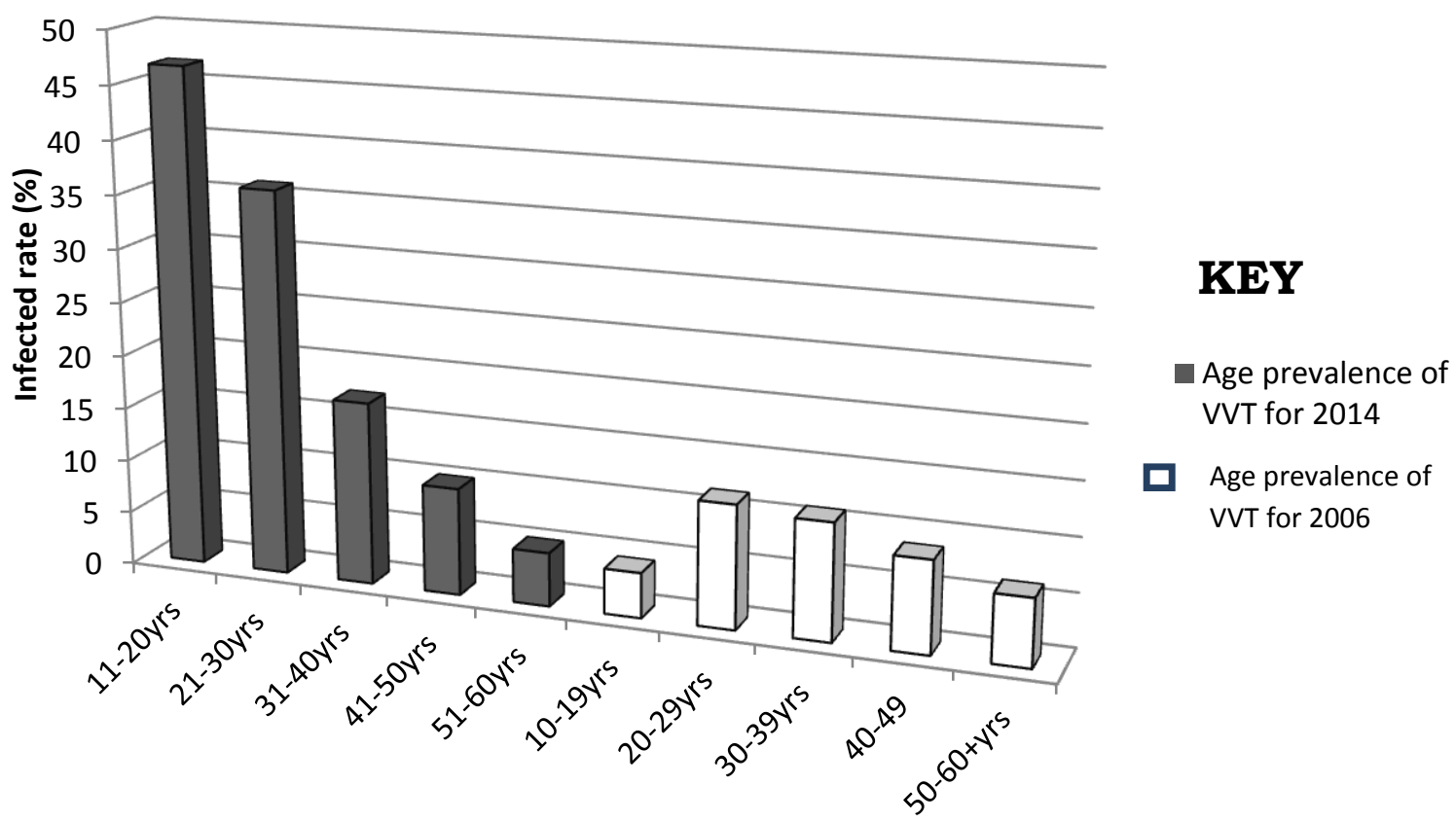

Age groups (years)

Figure 2b: Age related prevalence of VVT in the study populations of 2006 and 2014. 
Figure $2 b$, shows age related prevalence of $T$. vaginalis infection in the study population for the years 2006 and 2014. It is observed that age groups $20-29$ years, $30-$ 39 years and $40-49 y e a r s$ had infection rates of $16.5 \%$, $10.9 \%$ and $8.6 \%$ whereas least infection rate $(4.2 \%)$ was in age group 14-19 years in2006 while age groups 11 20,21 - 30, 31 - 40years had $46.7 \%, 36 \%, 17.1 \%$ respectively in 2014.In all age groups, prevalence of VVT was statistically higher in 2014 than it was in 2006 $(\mathrm{P}<0.05)$.

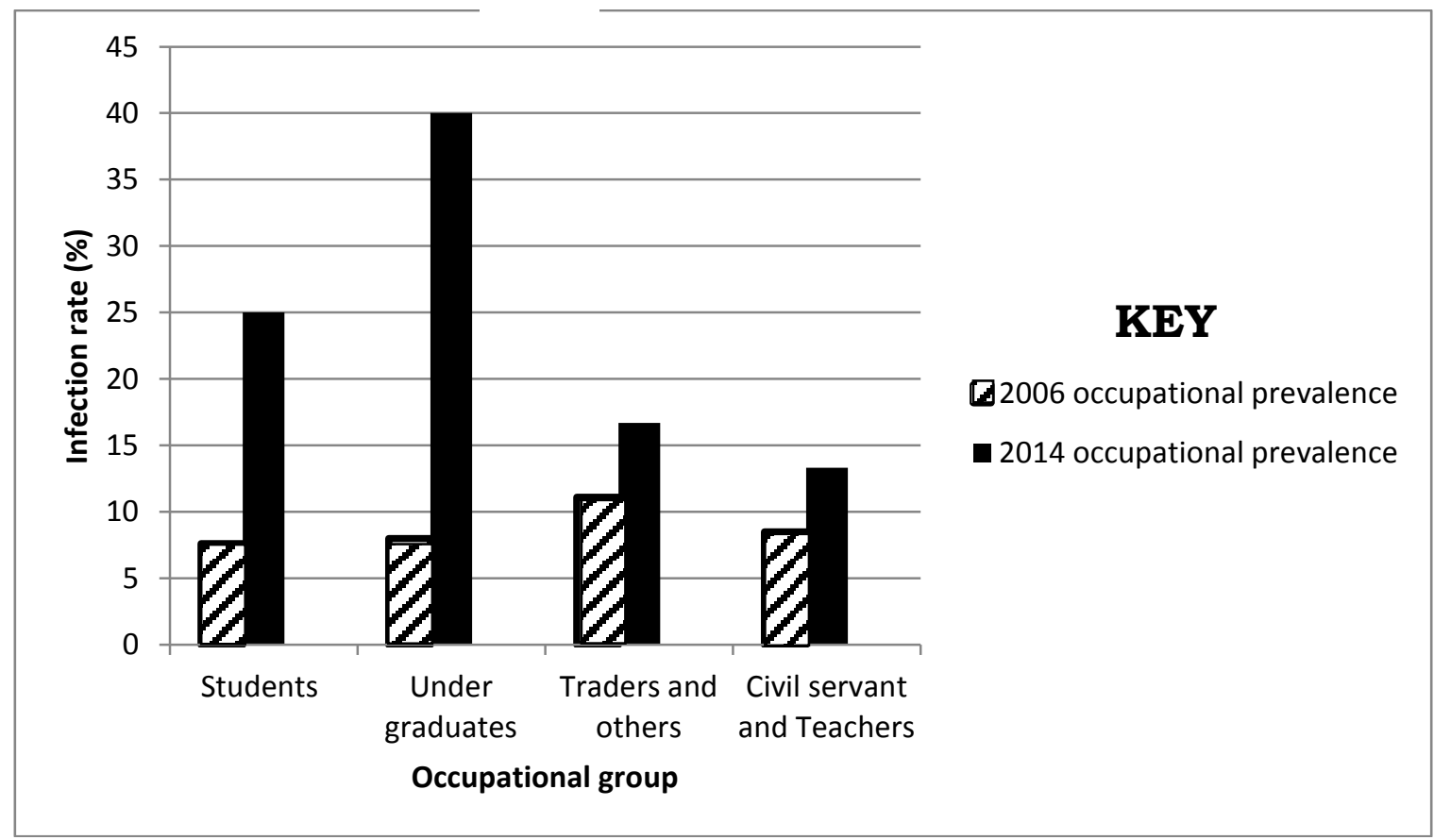

Figure 3: Occupation related prevalence of VVT in study populations of 2006 and 2014.

The result of occupation related prevalence of VVTin figure 3 , recorded undergraduate female subjects as the highest $(40 \%)$ risk bearers whereas the teachers had the least infection rate (13.3\%) in 2014. However, in 2006
VVT ranged between7.6\% (students) and 11.1\% (teachers).Chi-square test showed that the infection is not occupation related $(P>0.05)$; prevalence rates were generally higher in 2014 than 2006.

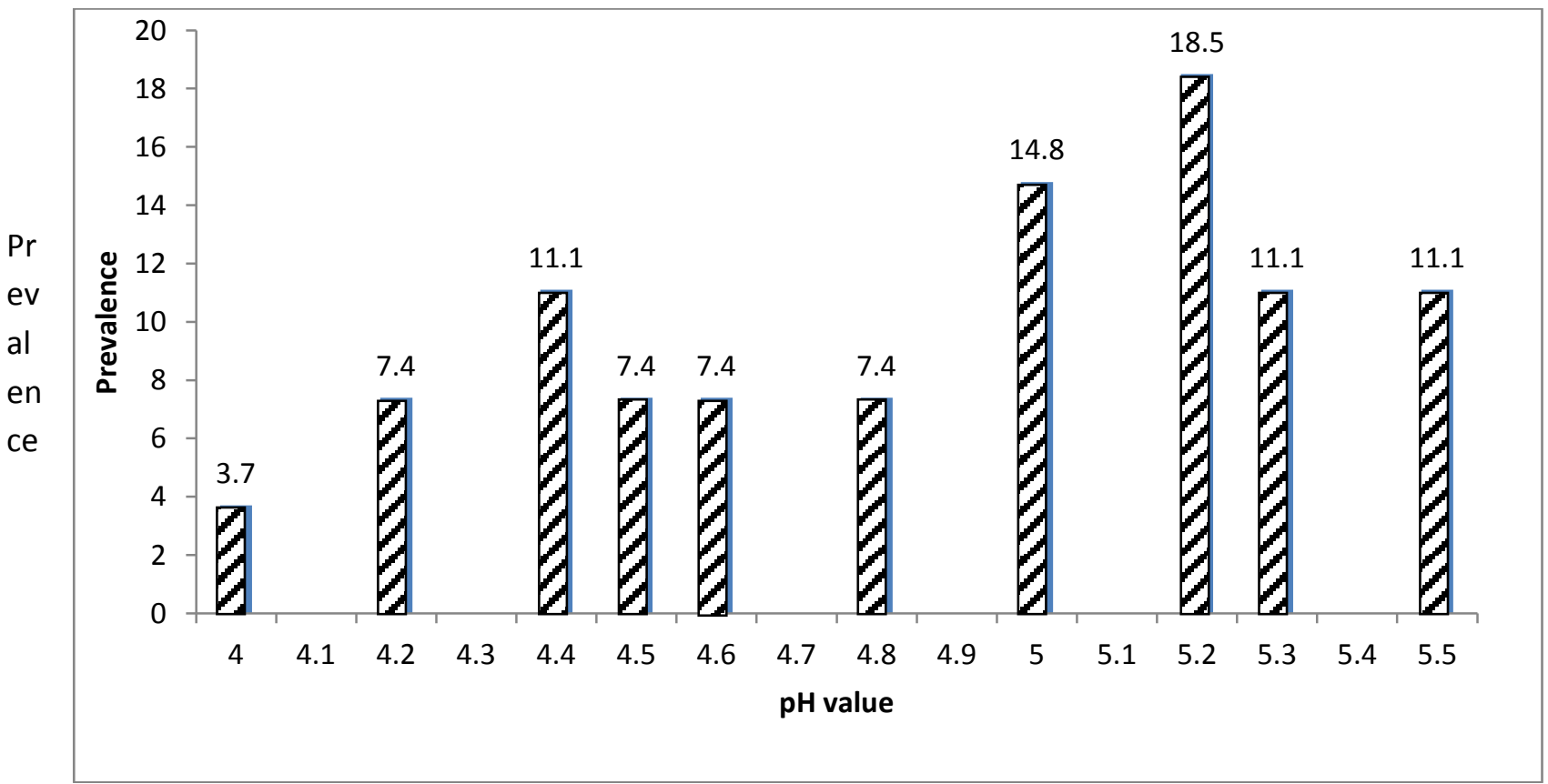

Figure 4: Relationship between vaginal $\mathrm{pH}$ and $T$. vaginalis. 
Figure 4, which is relationship between vaginal $\mathrm{pH}$ and $T$. vaginalis, shows that the parasite had its peak prevalence at $\mathrm{pH} 5.2$ with minimum at $\mathrm{pH}$ 4.0. It is evident that $T$. vaginalis thrives well within $\mathrm{pH}$ range of 4.2 and 5.5 .

\section{DISCUSSION}

In this study UPTH had higher $(9.7 \%$ and $30 \%)$ prevalence of vulvovaginal trichomoniasis (VVT) than BMSH ( $8 \%$ and $18.6 \%$ ) in 2006 and 2014 respectively. The grand prevalence was $22.5 \%$ which was statistically not location dependent $(P>0.05)$. This result $(22.5 \%)$ is however, much higher than $9.7 \%$ reported earlier at same location (Wokem, 2006) but fairly comparable to the report $(30 \%)$ of work done in the United State of America (Forest and Mink off, 1980). The higher prevalence of the infection in UPTH could be associated with the status of the hospital as the biggest teaching hospital in this Niger Delta zone, catering for women with complex gynecological problems rather than where the hospital is located. Fresh urine samples examined alongside vaginal swabs indicated slightly lower prevalence rates $(6 \% ; 18.3 \%)$ and $(10 \% ; 22.5 \%)$ for $\mathrm{BMSH}$ and UPTH respectively, while the grand prevalence for each of the samples was $12.7 \%$ (FU) and $15.6 \%$ (swab). Although Chi-square statistical analysis shows that the difference was not significant $(P>0.05)$, it was observed that the FU samples could not detectlight infections as much as did HVS. However, it was easier for the volunteers to give urine samples than swabs, again, collection and processing of FU was more cost effective than HVS. FU samples can therefore serve same purpose as HVS, particularly, in many rural communities in developing countries where for cultural or religious reasons; collection of vaginal swabs is regarded as a taboo. Polymerase chain reactiontest which is a more sensitive diagnostic tool is not routinely used where it is available, as affordability, skilland time constrain its regular use for screening sizable sample populations. The use of $\mathrm{FU}$ as diagnostic specimen makes it easier for researchers to screen subjects in remote areas with strong cultural barriers.

The prevalence of VVT among the pregnant (14\%) and non-pregnant (26.6\%) subjects as shown in the result, indicates close association with pregnancy though not statistically significant $(P>0.05)$. It was observed that age groups 21 to 41 years had the highest infection rates of $70 \%, 60 \%$ for the unmarried and $20 \%$, $16.7 \%$ for the married respectively. It could be so because this group is sexually active, hence the infection is sexually transmitted primarily. This finding agrees with a previous report (Wokem, 2006) though with lower infection rates of $16.5 \%, 10.9 \%$ and $8.6 \%$, for age groups 19-29, 29-39, and 39-49 years correspondingly but did not extend the work to marital status. It may also be attributed to common usage of wearable, a common practice of young females in hostels and at home. Sharing of toilet facilities in the school hostels and at home can promote cross-infection and reinfection among young adults, although sexual promiscuity seemed to be a major risk factor (Kreiss et al; 1994; Wokem, 2006). If $T$. vaginalis can be isolated in fresh urine as exemplified in this work, then the unhygienic practices of sharing urinary, towel, under wears and especially toilet facilities could be another major risk factor, hence, this mode of transmission is possible for the flagellate. These may have predisposed the young ones to the infection; the reflection was obvious in the occupational prevalence of VVT in the latter work. This finding is worrisome and calls for much concern.

The Undergraduates $(8 \%, 40 \%)$ and Secondary School girls $(7.6 \%, 25 \%)$ were mostly at risk while as the Teachers $(8.2 \%, 13.3 \%)$ were least at risk in both studies. The Teachers are more matured, more informed, and seemed to be more disciplined in terms of extramarital sex practices. In the case of the former, higher level of sexual indulgence as well as higherlevels of reproductive hormones favored the transmission and growth of the parasitic flagellate (Mascal, 1987; Anosike et al; 2004). The rate at which VVT declined when compared to other occupational groups, suggests multiple transmission routes which may likely promote other sexually transmitted diseases too. It is of particular interest to note that in general VVT showed a sharp prevalence upsurge in the latter study.

Trichomonas vaginalis thrives best at $\mathrm{pH} 5.2$, this observation agrees with an earlier report (Rein and Liang, 1999) that a normal vaginal $\mathrm{pH}$ in asymptomatic women suggests diagnosis of vulvovaginal candidiasis whereas an elevated $\mathrm{pH}$ depicts a diagnosis of bacterial vaginosis or trichomoniasis. It is evident that $T$. vaginalis can tolerate a wide range (4.2 to 5.5) of $\mathrm{pH}$ values and so, is an acidophile. This however, contraststhe report that $T$. vaginalis survives better at $\mathrm{pH} 4$ (Anosike, 2004). The results obtained in this study; even with lesssensitive diagnostic technique, points to the fact that trichomoniasis seemed to be significantly on the increase. Altering the $\mathrm{pH}$ of vagina to be basic could be incorporated inthe control measures of $T$. vaginalis.

In conclusion, if the implication of trichomoniasis as a co-factor in Human Immunodeficiency Virus (HIV) transmission and acquisition (Sorvillo, 2001) and perinatal transmission (Schwandi et al; 2008)have been confirmed to be true, coupled with an obvious multiple transmission routes, besides other health hazards associated with the infection, then the public health importance of VVT demands a more serious and urgent action plan to prevent pandemic and resurgence of not only VVT but more deadly HIV/AIDS and other sexually transmitted diseases. Trichomoniasis is gaining much prominence as asexually transmitted disease but surprisingly, there have been no much documentations nor control programmes for this neglected, common tropical, slow killer disease of young people. The eradication of HIV/AIDS might as well be an illusion, with ever increasing prevalence of trichomoniasis continually with us unchecked.

\section{REFERENCE}

Anosike, K. C., Okere, A. N., Nwoke, B. E. B., Onyeka, P. C and Njoku, A. J., 2004. Trichomonas vaginalis infection amongst pregnant women in urban Owerri Imo State, Nigeria. Nigerian Society for Parasitology Book of Abstracts. 
Arora, D. R and Arora, B., 2008. Trichomona svaginalis; Medical parasitology, $2^{\text {nd }}$ edition, CBS Publishers and Distributors, New Delhi, Bangalore, India. pp 41-43.

Dennis, M. Y. X., Nuttle, et al; 2011. Evolution of human specific neural SRGAP2 genes by incomplete segmental duplication. Cell. 149, (4): 912-922.

Forest, J. M and Minkoffi, H., 1980. Condom use relative to knowledge of sexually transmitted disease prevention, method of birth control and past or present infection. Journal of Community Health.19:395-407.

Fouts, A. C and Kraus, S. J., 1980. Trichomonas vaginalis: re-evaluation of its clinical presentation and laboratory diagnosis. Journal of Infectious Diseases, 141:137-143.

Hobbs, M. M., Kzembe, P., Reed, A. W., Miller, W. C., Nkata, E and Zimba D., 1999. Trichomoniasis as a cause of urethritis in Malawian men. Sex transmitted diseases, 26:381-387.

Kissinger, $P$ and Adamski, A., 2013. Trichomoniasis, Sex Transmitted Infections. 86, (6): 426-433.

Kreiss, J., Willerford, D. M., Hensel, M., Emonly, W., Plummer, F and Ndinya-Achola, J., 1994. Association between cervical inflammation and cervical shedding of human immunodeficiency virus DNA. Journal of Infectious Diseases. 170:15971601.

Mascal, T. C., 1987. Diagnosis of Trichomonas vaginalis infection by PCR using vaginal swab samples. Journal of Clinical Microbiology. 36: 3206-3210.

Rein, M. F and Liang, B. A., 1999. Diagnosis of infectious vaginitis. Case study and commentary. Clinical Outcomes. 6, (4): 45-54.

Sardana, S., Sodhani, P., Agarwal, S. S., Sehgal, A., Roy, M and Singh, V., 1994. Epidemiologic analysis of Trichomonas vaginalis infection in inflammatory smears. Acta Cytology, 38:693-697.

Schwandt, A., Williams, C and Beigi, R. H., 2008. Perinatal transmission of Trichomonas vaginalis: a case report. Journal of Reproductive Medicine. 53: 59- 61.

Sorvillo, F., Smith, L., Kemdt, P and Ash, L., 2001. Trichomonas vaginalis, HIV and AfricanAmericans. Emergency Infectious Disease.7:927-32.

Sutton, M., Slemberg, M and Koumons, E. H., et al., 2007. The prevalence of Trichomonas vaginalis infection among reproductive age women in the United States, 2001- 2004.Clinical Infectious Diseases. 45, (10): 1319-1326.
Vaisrub, L. S., 1989. Trichomonas vaginalis as a cause of urethritis in men. Sexually Transmitted Disease. 26:381-387.

W.H.O., 2011. Prevalence and incidence of selected sexually transmitted infections- Chlamydia trachomalis, Neisseria gonorrhaoe, Syphlis and Trichomonas vaginalis. Geneva, World Health Organization.

Wokem, G. N., 2006. Trichomonas vaginalis infection in some parts of Niger Delta Region, Rivers State, Nigeria. Nigerian Journal of Parasitology. 27:6872 . 